\title{
TITLE:
}

\section{A GENERAL COMPARISON OF THE CNIDARIA AND TUNICATA}

AUTHOR(S):

Hadzi, Jovan

\section{CITATION:}

Hadzi, Jovan. A GENERAL COMPARISON OF THE CNIDARIA AND TUNICATA. PUBLICATIONS OF THE SETO MARINE BIOLOGICAL LABORATORY 1973, 20: 175-178

\section{ISSUE DATE:}

1973-12-19

URL:

http://hdl.handle.net/2433/175779

RIGHT: 


\title{
A GENERAL COMPARISON OF THE CNIDARIA AND TUNICATA
}

\author{
†JovAN HADŽI \\ Biološki Inštitut, Slovenska Akademija, Znanosti in Umetnosti, Ljubljana
}

At first glance it does not seem reasonable to compare the Cnidaria with the Tunicata, as the former take the basic, the latter a much higher position of the natural system of Eumetazoa with two phyla between, the Polymeria and Oligomeria. Therefore the two groups cannot have any relationships and it is useless to find out homologies other than those concerning the most elementary structures, as for instance ectoderm, endoderm, mesohyl, and formation of mouth.

The situation is different if we undertake a comparison from another viewpoint; then it can lead to successful results. We must take into account that both groups have a most important quality in common which has affected their evolution to a high degree, i.e. the change from the motile to the sessile way of life which has been followed by a secondary return to a free-living habit. This change in the living habit gave rise to corresponding changes in the morphology and feeding which are correlated with the special basic structures of these two different groups. The old adage is true: "Si duo faciunt idem, non est idem" (if two persons do the same, it is not the same).

The zoologists agree on that the change mentioned from the motile to the sessile living habit has followed principally the same rules in the Tunicata as well as in the other groups of animals. The acquisition of the sessile way of life represents a secondary step of evolution which has been followed by regressive changes of the general organization and behaviour. Special attention must be called to the consequence of colonial growth which gave rise to the formation of cormi. On the other hand, the sessile habit can be followed by the evolution of a planktonic generation again due to progressive steps of evolution.

Is it reasonable or probable to assume that these generally valid principles should not be true for the Cnidaria? Most zoologists still believe up to the present day what E. HAECKEL has emphasized, namely that the Cnidaria have originated from a primitive form, the so-called "gastrea," the existence of which has been deduced from an actual ontogenetical stage of development of the recent Cnidaria. This free-living gastrea is thought to have given rise first to a sessile hydropolyp which then should have been followed by the scyphopolyp and finally the anthopolyp. This way of evolution should be considered as progressive, which is contrary to expectations if we try to reconcile it with the general principles. There are some other opinions on the origin of the Cnidaria, as for instance, the idea of the medusa being the primary form. But this is not the place to go into the details of such problems.

It is now nearly 30 years since I tried to demonstrate that the old opinion of the 
true nature and phylogeny of Cnidaria is not the only possible one, but, instead, that it is improbable and not applicable at all. At that time I established a new idea which I called the theory of the turbellarian origin of Cnidaria and since then I have produced substantial evidence for my theory in numerous publications. It has given rise to an extensive discussion for and against it but I do not believe I am wrong in maintaining that in all discussions no convincing argumentation has been given which could disprove my theory. Actually, as a result different opinions have remained.

In accordance with my opinion, I take a sessile, radial-symmetrically constructed and upright cnidarian polyp as the primitive form which feeds on individual prey. It is considered as originated from acoelic turbellarian ancestors which crept actively on a substratum. The acquisition of asexual reproduction was followed by colonial growth to form cormi which led in some cases to polymorphism, and it was also followed by the development of a free-living medusoid generation which could finally become independent. Such transitional changes from the motile to the sessile living habit have been repeated very often. They are possible only in the medium of water, with the exception of parasites which behaved in the same way also in the terrestrial environment. Of course there have been important differences which correspond to and depend on the organization level and mode of feeding (predators, filter feeders) and also on the phylogenetic age. In any case we have to deal with more or less short blindly ending side branches of the phylogenetic tree.

It was in the high systematic rank of the megaphylum Chordata that this has happened the last time in a very substantial way. This is the reason why they have been chosen for this comparison. Of course I know that, considering the general organization level, the differences between the Cnidaria and Tunicata are very important. The Tunicata represent Chordonia, they are secondarily polymerous, they possess an internal branchial system and a dorsal chorda (at least during their development) and so on. Therefore there are many and important differences between both groups.

On the other hand, there are many similarities which are important, too. A fairly large number of them must be considered as secondary ones which do not exist in other Chordonia. This is true for the planktonic larva which possesses a tail and which gave rise to the Appendicularia by way of neoteny. Such a developmental stage seems to be completely lacking in the Cnidaria because their larvae are not able to take in food.

Those forms which have a solitary individual polypoid life habit must be considered as the most primitive recent Tunicata. Because of their special feeding habit (i.e. the filtration of sea water through the ciliated gill slits, which mode is considered as inherited from the Branchiostoma-like ancestors) the Tunicata did not form a tentacular crown. Therefore the shape of their body does not resemble very much a polypoid form as they possess only a small corona of cirri inside the incurrent opening. With regard to the position of the anus they followed the principle of the euproct Amera as the intestinum has been moved near to the mouth opening. Another 
complication is the formation of the peribranchial chamber.

It seems clear that the sessile way of life led to a reduction of the general organization to a fairly high degree. This is true in a marked way for the muscular system, the complete caudal region and the chorda dorsalis. Furthermore, the heart and the circulatory system, the system of the polymerized coelomic cavity inclusive of mesohyl, the central nervous system, parts of the gonads and other parts have been reduced also. Considering the Cnidaria we meet with similar phenomena of reduction if we agree that the evolution went on from the Anthozoa to the Scyphozoa and Hydrozoa.

Up to the present day, the solitary polypoid Ascidia represent the dominating forms of the Tunicata and an "ascidium" can be taken as being equivalent to a polyp of the Cnidaria. Steps of parallel evolution gave rise to the formation of cormi by asexual reproduction whereby the Synascidia have been originated. By the diminution of the individual polypoid forms, incomplete individuals or apersonal parts originated to form stolons. This has happened rather to a lower degree than in the Cnidaria due to the high degree of individualization of the Chordata. Only in a few cases-as for instance in Colella-has it happened that also the cormi have changed into individuals.

The following steps of evolution of Tunicata led to a corresponding result as in the Cnidaria and consisted of the transition to a pelagic way of life. However, this way of evolution is missing in the Oligomeria, though they have also changed to a sessile life habit. From a "synascidia" a "thalia" has originated which can be considered as equivalent to a medusa. The excurrent siphon moved to the side opposite to the incurrent siphon, the few muscles which remained changed to circular bands in consequence of which the "thalia" was able to swim by rhythmical contractions, as does the medusa by jet pulsations in a different way but with the same effect.

The Pyrosoma represents a clear example of an individualized free-swimming cormus (=colony). In the Thaliacea the structures became much more complicated and peculiar but there is no time to go into more details here. It is sufficient to note that in this group we meet structures which correspond to the individualized and polymorphic cormi of the free-living Siphonophora.

The difference between "ascidium" and "thalia" is not so important as that between polyp and medusa. The reason is that the body axis has changed in the medusa by $180^{\circ}$ as the mouth opening moved to the under side of the body. On the other hand, in the Tunicata the excurrent siphon has moved to a lateral position by $90^{\circ}$ only.

Finally I should like to call attention to three micro-parallels:

1. In the Cnidaria as well as in the Tunicata the more primitive species are represented only by the benthonic polypoid forms whereas the pelagic medusoid form originated later.

2. In both phyla the more primitive forms possess more complicated endodermal structures which consist of the septa, respectively taenioles of the Cnidaria on the one side, and the gill slits of the branchial sac of the Tunicata on the other. The 
number of these structures is reduced later and they finally disappear completely. 3. Nephridia are lacking in both recent groups. With respect of Cnidaria I believe that this lack is due to secondary steps of evolution whereas the followers of the old view believe this characteristic to be basic. Considering the Tunicata on the other hand, without doubt the lack of nephridia is due to a secondary reduction.

\section{Conclusion}

I believe I have demonstrated that the comparison outlined of Cnidaria and Tunicata gives positive results, though they represent quite different groups of animals. The comparative morphology elucidates that there are numerous fascinating similarities, inspite of all basic and well understood differences. In each case we deal with certain regularities which are not, of course, homologies but examples of parallel evolution. On the other hand, as they have not originated accidentally they can help to a better understanding and interpreting of the structures and life habits of the Cnidaria. 